\title{
ARTICLE OPEN \\ Me, myself, bye: regional alterations in glutamate and the experience of ego dissolution with psilocybin
}

\author{
N. L. Mason (D) ${ }^{1}$, K. P. C. Kuypers (iD) ${ }^{1}$, F. Müller ${ }^{1,2}$, J. Reckweg (iD) ${ }^{1}$ D. H. Y. Tse ${ }^{1}$, S. W. Toennes (iD ${ }^{3}$, N. R. P. W. Hutten ${ }^{1}$, J. F. A. Jansen ${ }^{4,5}$, \\ P. Stiers ${ }^{1}$, A. Feilding ${ }^{6}$ and J. G. Ramaekers ${ }^{1}$
}

There is growing interest in the therapeutic utility of psychedelic substances, like psilocybin, for disorders characterized by distortions of the self-experience, like depression. Accumulating preclinical evidence emphasizes the role of the glutamate system in the acute action of the drug on brain and behavior; however this has never been tested in humans. Following a double-blind, placebo-controlled, parallel group design, we utilized an ultra-high field multimodal brain imaging approach and demonstrated that psilocybin $(0.17 \mathrm{mg} / \mathrm{kg})$ induced region-dependent alterations in glutamate, which predicted distortions in the subjective experience of one's self (ego dissolution). Whereas higher levels of medial prefrontal cortical glutamate were associated with negatively experienced ego dissolution, lower levels in hippocampal glutamate were associated with positively experienced ego dissolution. Such findings provide further insights into the underlying neurobiological mechanisms of the psychedelic, as well as the baseline, state. Importantly, they may also provide a neurochemical basis for therapeutic effects as witnessed in ongoing clinical trials.

Neuropsychopharmacology (2020) 45:2003-2011; https://doi.org/10.1038/s41386-020-0718-8

\section{INTRODUCTION}

Psychedelics are a class of psychoactive substances, which induce profoundly altered states of consciousness, including transient and dose-dependent distortions in the subjective experience of one's self [1]. Termed ego dissolution [2], this phenomenon is characterized by the reduction in the self-referential awareness that defines normal waking consciousness, ultimately disrupting self-world boundaries and increasing feelings of unity with others' and one's surroundings [3]. Importantly, there is a renewed interest in the use of these substances in the treatment of various psychiatric conditions characterized by distortions of the selfexperience $[4,5]$. Recent clinical studies have suggested that these substances can increase well-being [4, 6-11] and provide therapeutic relief for those suffering from anxiety, depression, and addiction [4, 9, 12-15].

Converging evidence suggests that classical psychedelics, such as lysergic acid diethylamide (LSD), psilocybin, and dimethyltryptamine (DMT), stimulate serotonin $\left(5-\mathrm{HT}_{2 \mathrm{~A}}\right)$ receptors located on cortical pyramidal neurons, which is the suggested primary mechanism of action for their hallucinogenic effect [16-22]. Nevertheless, accumulating evidence from preclinical studies also emphasizes the role of the glutamate system in $5-\mathrm{HT}_{2 \mathrm{~A}}$ receptormediated effects on brain function [19, 23, 24] and behavior [17]. Specifically, it has been suggested that activation of $5-\mathrm{HT}_{2 \mathrm{~A}}$ receptors leads to a glutamate-dependent increase in activity of pyramidal neurons in the prefrontal cortex $[18,19,25,26]$, subsequently modulating prefrontal network activity [16]. Furthermore, the increase in extracellular glutamate has been suggested to activate AMPA receptors located on the same neurons, increasing expression of brain-derived neurotrophic factor (BDNF) $[16,27,28]$, a protein implicated in neuronal survival and growth, and decreased in pathological populations [29]. Taken together, it has been suggested that $5-\mathrm{HT}_{2 \mathrm{~A}}$ receptor-mediated glutamate release is the final common pathway for the acute actions of psychedelics, and a potential underlying mechanism of therapeutic effects [16]. However, no study has investigated the acute effect of a psychedelic on brain glutamate levels in humans, and its relationship with established psychedelic-induced alterations on brain function and behavior.

The present study was designed to establish the contribution of glutamate to the psychedelic state by using ultra-high field (7T) proton magnetic resonance spectroscopy (MRS) that allows in vivo assessment of glutamate in designated brain areas. First, we assessed the acute influence of the classic psychedelic, psilocybin, on glutamate concentration levels in the human brain. Then we assessed the association between glutamate levels, and key features of the psychedelic state, e.g., the experience of ego dissolution, and disrupted resting state network (RSN) functional connectivity (FC). It has been repeatedly found that LSD, DMT, and psilocybin decrease within-network connectivity in several RSNs while increasing connectivity across such networks [30-36]. Affected RSNs include the default mode network (DMN), an interconnected group of brain structures including the medial prefrontal cortex (mPFC), posterior cingulate cortex, and inferior parietal lobule [37, 38]. Importantly, the DMN in particular has become closely associated with self-referential mental

\footnotetext{
${ }^{1}$ Department of Neuropsychology and Psychopharmacology, Faculty of Psychology and Neuroscience, Maastricht University, P.O. Box 616, 6200 MD Maastricht, the Netherlands; ${ }^{2}$ Department of Psychiatry (UPK), University of Basel, Basel, Switzerland; ${ }^{3}$ Institute of Legal Medicine, University of Frankfurt, Kennedyallee 104, D-60596 Frankfurt/Main, Germany;

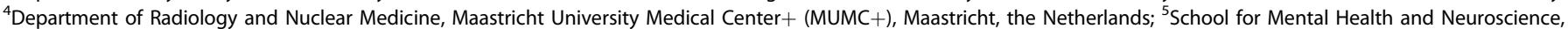
Maastricht University Medical Center, P. Debyelaan 25, Maastricht, the Netherlands and ${ }^{6}$ The Beckley Foundation, Beckley Park, Oxford OX3 9SY, UK Correspondence: N. L. Mason (natasha.mason@maastrichtuniversity.nl) or J. G. Ramaekers (j.ramaekers@maastrichtuniversity.nl)
}

Received: 30 March 2020 Accepted: 14 May 2020

Published online: 23 May 2020 
activity [37, 39], and psychedelic-induced alterations in DMN function have been repeatedly implicated in the experience of ego-dissolution [33, 40-42].

Relative glutamate concentrations were quantified in the mPFC and the hippocampus. These areas were chosen based on previous anatomical, functional, and behavioral evidence implicating them as potential key regions in modulating the psychedelic experience. Specifically, both areas contain a high density of 5$\mathrm{HT}_{2 \mathrm{~A}}$ receptors [43], which is among the most abundant 5-HT receptor expressed in these regions [44, 45]. Functionally, preclinical studies have shown increased glutamate concentrations in the mPFC after 5- $\mathrm{HT}_{2 \mathrm{~A}}$ agonism [18, 19, 25, 26], whereas in humans increased glucose, indicative of higher metabolic demands due to increased cell excitability, has been found in frontal and temporal regions after psilocybin [46]. Finally, both areas anatomically overlap with the DMN, with the mPFC recognized as a major hub [37, 38], and a decoupling between the DMN and medial temporal lobe (MTL; especially hippocampal regions) hypothesized to be a key mechanism in the experience of ego dissolution [47-49].

Resting state functional magnetic resonance imaging (rsfMRI) was used to assess RSN FC. Within-network FC assessment followed the approaches of previous studies to allow for comparability [32], and subjective state was characterized via a well-established altered states of consciousness questionnaire $[2,50]$, and a validated questionnaire to assess ego dissolution [1]. As MRS captures a range of brain metabolites, we also performed an exploratory analysis to assess whether psilocybin affected other metabolites of interest, including $\gamma$-aminobutyric acid (GABA) [17], and markers of neuronal integrity and glial activation, including $n$ acetyl-aspartate (NAA), and myo-inositol (ml).

\section{MATERIALS AND METHODS}

A detailed description of the experimental procedure, image acquisition, MRS quantification, and rsfMRI analysis is provided in the Supplementary methods, and briefly summarized here.

The present study employed a randomized, placebo-controlled, double-blind, parallel group design. Sixty healthy participants, with previous experience with a psychedelic drug but not within the past 3 months, were allocated to a treatment condition $(0.17$ $\mathrm{mg} / \mathrm{kg}$ psilocybin or placebo, p.o.). Groups were matched for age, sex, and education level.

This study was conducted according to the code of ethics on human experimentation established by the declaration of Helsinki (1964) and amended in Fortaleza (Brazil, October 2013) and in accordance with the Medical Research Involving Human Subjects Act (WMO) and was approved by the Academic Hospital and University's Medical Ethics committee. All participants were fully informed of all procedures, possible adverse reactions, legal rights and responsibilities, expected benefits, and their right for voluntary termination without consequences.

Image acquisition

Participants underwent structural MRI ( 50 min post treatment), single-voxel proton MRS in the MPFC (65 min post) and hippocampus (95 min post), and fMRI (102 min post), during peak subjective drug effects. Images were acquired on a MAGNETOM 7T MR scanner.

Spectroscopic voxels were placed by a trained operator at the mPFC (voxel size $=25 \times 20 \times 17 \mathrm{~mm}^{3}$ ) and the right hippocampus $\left(\right.$ voxel size $\left.=37 \times 15 \times 15 \mathrm{~mm}^{3}\right)$. Spectra were acquired with the stimulated echo acquisition mode [51] sequence (TE $=6.0 \mathrm{ms,}$ $\mathrm{TR}=5.0 \mathrm{~s}, 64$ averages). Outcome measures for MRS were concentration ratios of glutamate, GABA, NAA, and $\mathrm{ml}$, to total Creatine (tCr, Creatine + Phospho-Creatine), because using $\mathrm{tCr}$ as the internal reference inherently corrects for variabilities caused by transmit or receive RF inhomogeneity, magnetic field drift, and CSF inclusion in the voxel [52].

In addition, 258 whole-brain EPI volumes were acquired at rest $\left(\mathrm{TR}=1400 \mathrm{~ms} ; \mathrm{TE}=21 \mathrm{~ms}\right.$; field of view $=198 \mathrm{~mm}$; flip angle $=60^{\circ}$; oblique acquisition orientation; interleaved slice acquisition; 72 slices; slice thickness $=1.5 \mathrm{~mm}$; voxel size $=1.5 \times 1.5 \times 1.5$ $\mathrm{mm}$ ). During scanning, participants were shown a black cross on a white background, and instructed to focus on the cross while clearing their mind and laying as still as possible.

\section{Processing of imaging data}

Spectroscopy data was analyzed with LCModel version $6.3-1 \mathrm{H}$.

Resting state data was processed and analyzed using the CONN toolbox 18.b [53]. All volumes were realigned, unwarped, segmented into gray and white matter and cerebrospinal fluid, normalized into a standard stereotactic space (Montreal Neurological Institute), and smoothed with a $6 \mathrm{~mm}$ full width at half maximum Gaussian kernel.

Independent component analysis (ICA) was performed using group-ICA procedures implemented in the CONN toolbox following previously described methods [54]. Independent components were restricted to 20 in order to allow comparisons with 10 established RSNs [55] and previous studies on psilocybin [42] and LSD $[32,33]$.

\section{Subjective state}

The 5 Dimensions of Altered States of Consciousness (5D-ASC) scale [50] and the Ego Dissolution Inventory (EDI) [1] were administered 360 min after drug administration, as retrospective measures of drug effects.

\section{Pharmacokinetic measures}

Venous blood samples were collected after treatment administration (at 80,150, and $360 \mathrm{~min}$ ) in order to assess concentrations of psilocin, the main metabolite of psilocybin.

\section{Statistical analysis}

Statistical analysis of metabolite concentration levels and questionnaire responses were conducted in IBM SPSS Statistics 24 using nonparametric Mann-Whitney $U$ tests.

For the assessment of within-network FC, the unthresholded, binarized ICA component images were compared between placebo and drug conditions (two-sample $t$-test). Parametric statistics were used (voxel threshold $p<0.001$ uncorrected, cluster threshold $p<0.05$ cluster-size, false discovery rate (FDR) corrected, two-sided).

For the assessment of between-network FC, unthresholded, binarized maps of RSNs obtained from the ICA analysis were imported as ROls and the weighted sums of the time series were extracted. Time courses between all RSNs were then compared for both conditions using bivariate correlations. The resulting correlation coefficients were compared between placebo and drug conditions (two-sample $t$-test). Results were corrected for multiple comparisons using FDR.

Canonical correlations [56] were conducted to evaluate the association between psilocybin-induced changes in (i) relative glutamate concentration levels in the MPFC and hippocampus, (ii) ratings of ego dissolution, including two dimensions of the 5DASC (oceanic boundlessness and anxious ego dissolution) and scores on the EDI, and (iii) within-network resting state $\mathrm{FC}$, using extracted connectivity strength (beta) values. Variables were separated into two sets; set 1 included biological variables as predictors [(i) and (iii)] and set 2 included the subjective variables as criterion (ii). An iterative imputation approach was performed to fill in missing data points, when applicable.

The alpha criterion of significance of all tests was assumed at $p<0.05$. 
A.

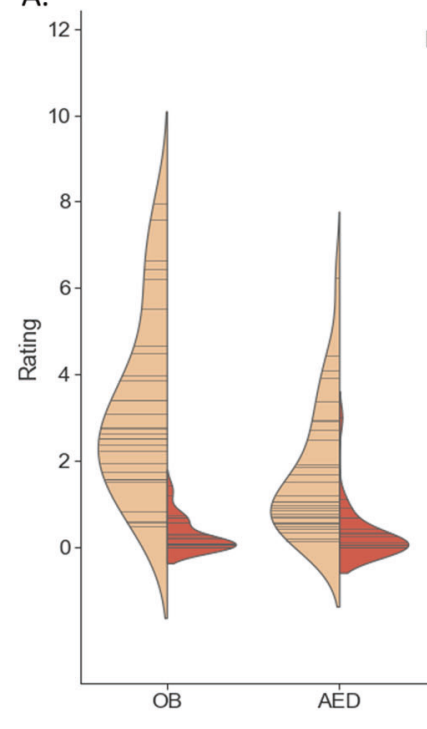

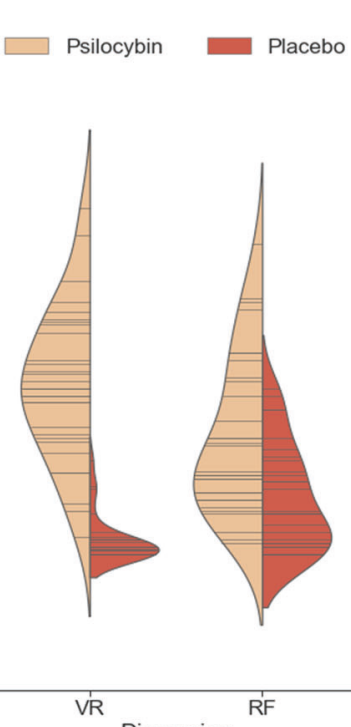

B.

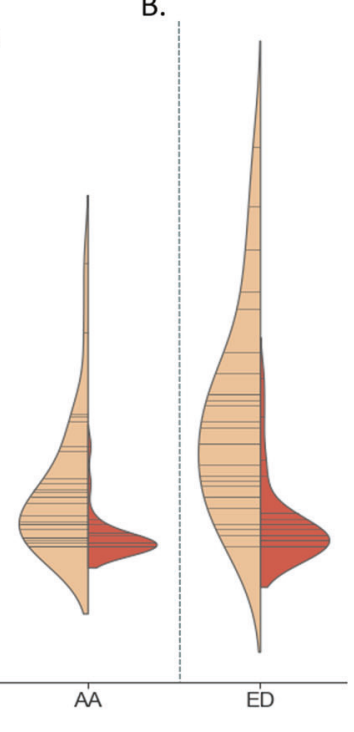

Fig. 1 Retrospective ratings of drug effects. Violin plots displaying reported scores on the 5 main dimensions of the 5D-ASC (a), ratings on the ego dissolution inventory (b) for each treatment group. Each stick in the violin indicates a data point, whereas the density is scaled to the relative count across all bins.

\section{RESULTS}

Demographic variables and psilocin concentration levels

The psilocybin group $(n=30)$ and the placebo group $(n=30)$ did not differ in respect to demographic variables (Table S1).

Mean (S.E.) concentrations of psilocin in serum are given in Table S2. Concentrations reached a peak $80 \mathrm{~min}$ postdrug administration $(15.61 \pm 1.66 \mathrm{ng} / \mathrm{mL})$, and then began to fall (360 $\mathrm{min}$ post $4.85 \pm 0.54 \mathrm{ng} / \mathrm{mL}$ ). The measured concentrations are in accordance with the applied oral dose [57].

Acute effect of psilocybin on subjective state Administration of psilocybin was associated with increased ratings on all (sub)dimensions of the 5D-ASC $(U=13.5-225 ; p \leq 0.001$ effect size $=0.43-0.84$, Fig. $1 \mathrm{a}$; S1), and on the EDI $(U=91.5, p<$ 0.001 , effect size $=0.67$, Fig. $1 \mathrm{~b}$ ).

MRS results

Spectral quality for each treatment condition is reported in Table 1. Overview of data points that did not meet the data quality criteria check can be found in Table S6.

Medial prefrontal cortex. As hypothesized, glutamate/total creatine (glutamate) in the MPFC was higher after psilocybin, compared with placebo (mean \pm S.E.; psilocybin: 1.23 \pm 0.02 ; placebo: $1.14 \pm 0.02, \quad U=200.50, \quad p=0.01$, effect size $=0.80$, Fig. 2a).

In addition, tNAA/total creatine (psilocybin: $1.41 \pm 0.03$; placebo: $1.31 \pm 0.02, U=210.0, p=0.02$, effect size $=0.72$, Fig. $2 b$ ), and GABA/total creatine (psilocybin: $0.17 \pm 0.01$; placebo: $0.14 \pm 0.01$, $U=66.0, p=0.01$, effect size $=0.99$, Fig. $2 \mathrm{~d}$ ) were higher after psilocybin, compared with placebo.

Hippocampus. In contrast, glutamate in the hippocampus (psilocybin: $0.77 \pm 0.03$; placebo: $0.88 \pm 0.03, U=163.50, p=0.03$, effect size $=0.69$, Fig. $2 \mathrm{c}$ ) was lower after psilocybin, compared to placebo.

No other significant differences were seen between groups in regards to relative concentrations of GABA, tNAA, $\mathrm{ml}$, or total creatine concentration. See Table S3 for means of all investigated metabolite concentration, additional metabolites acquired in the
Table 1. Mean (SD) spectral quality per group. Only data points with an SNR $>10$, FWHM $<0.1$, and a CRLB $<20 \%$ were included in the final analysis.

\begin{tabular}{|c|c|c|c|c|}
\hline Parameter & Psilocybin & Placebo & $t$ value & $P$ valu \\
\hline \multicolumn{5}{|c|}{ Medial prefrontal cortex } \\
\hline \multicolumn{5}{|c|}{ Relative Cramer-Rao lower bound (\%); $n$} \\
\hline Glutamate & 2.62 (0.57); 24 & $2.71(0.60) ; 28$ & -0.54 & 0.58 \\
\hline GABA & 13.33 (3.52); 15 & $14.65(3.33) ; 17$ & -1.08 & 0.29 \\
\hline$N A A+N A A G$ & 2.37 (0.49); 24 & $2.32(0.55) ; 28$ & 0.36 & 0.71 \\
\hline Myoinositol & 4.33 (2.14); 24 & 4.11 (1.42); 28 & 0.45 & 0.65 \\
\hline $\begin{array}{l}\text { Signal to } \\
\text { noise ratio }\end{array}$ & $36.87(4.77)$ & $37.96(6.52)$ & -0.67 & 0.50 \\
\hline $\begin{array}{l}\text { Full-width at half- } \\
\text { maximum } \\
\text { peak height }\end{array}$ & $0.04(0.01)$ & $0.04(0.01)$ & -0.307 & 0.76 \\
\hline \multicolumn{5}{|l|}{ Hippocampus } \\
\hline \multicolumn{5}{|c|}{ Relative Cramer-Rao lower bound (\%); $n$} \\
\hline Glutamate & $5.85(2.32) ; 21$ & 5.00 (1.73); 25 & 1.43 & 0.16 \\
\hline GABA & 16.60 (1.67); 5 & 14.50 (3.07); 8 & 1.39 & 0.19 \\
\hline$N A A+N A A G$ & $2.90(0.77) ; 21$ & 2.96 (0.93); 25 & -0.22 & 0.83 \\
\hline Myoinositol & $4.70(1.26) ; 20$ & $4.62(3.12) ; 24$ & 0.10 & 0.92 \\
\hline $\begin{array}{l}\text { Signal to } \\
\text { noise ratio }\end{array}$ & $20.57(5.61)$ & $21.16(6.86)$ & -0.31 & 0.75 \\
\hline $\begin{array}{l}\text { Full-width at half- } \\
\text { maximum } \\
\text { peak height }\end{array}$ & $0.07(0.01)$ & $0.06(0.01)$ & 1.80 & 0.08 \\
\hline
\end{tabular}

$N$ refers to the number of data points that met the criteria, per metabolite, per group, and were included in the analysis.

spectra, and Figure S2 for representative spectra and voxel placement.

Resting state networks

After quality control, the final sample consisted of 22 participants in the psilocybin group and 26 in the placebo group. There were 
A.

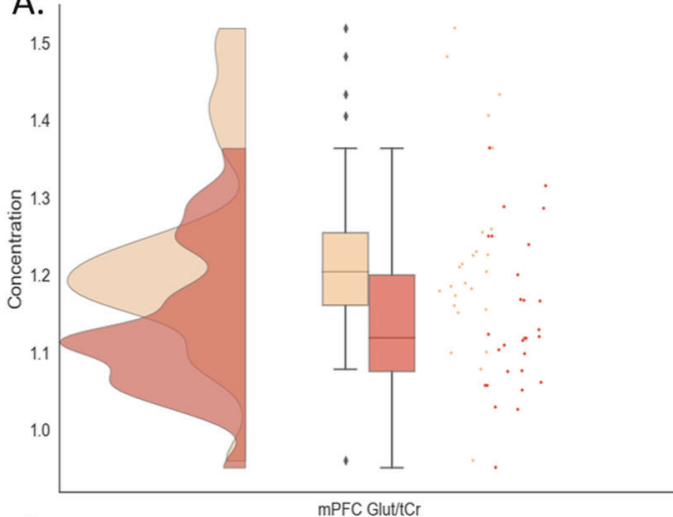

C.

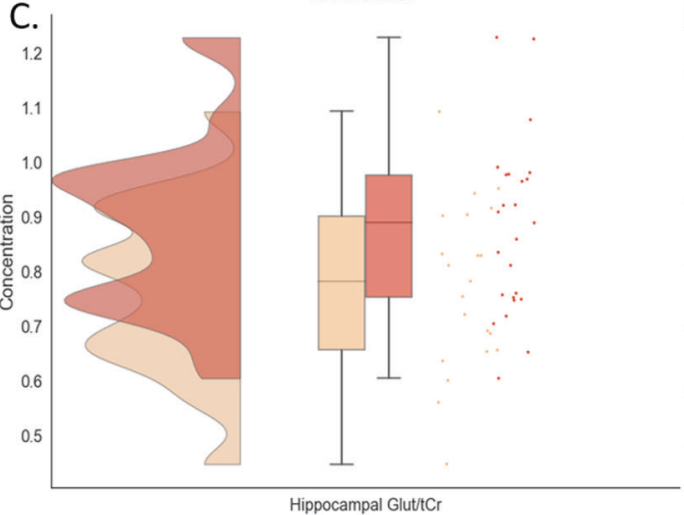

B.
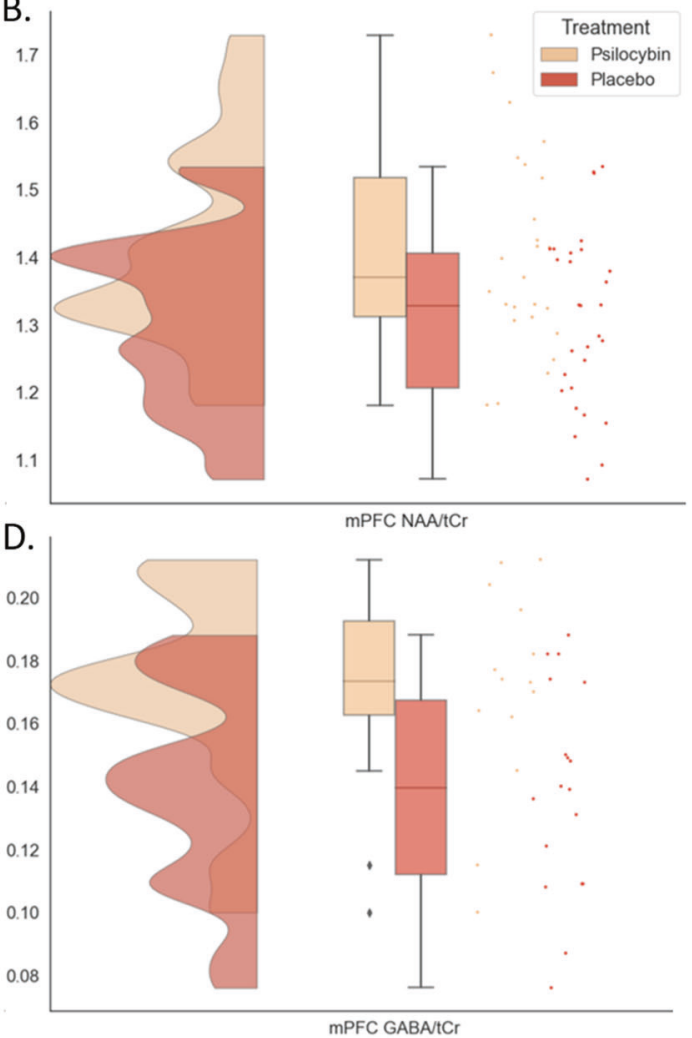

Fig. 2 Raincloud plots displaying metabolite concentrations in the mPFC and the hippocampus, which demonstrated significant differences between treatment groups. a glutamate in the MPFC, $\mathbf{b}$ NAA in the MPFC, $\mathbf{c}$ glutamate in the hippocampus, $\mathbf{d}$ GABA in the mPFC. The plot consists of a probability density plot, a boxplot, and raw data points. In the boxplot, the line dividing the box represents the median of the data, the ends represent the upper/lower quartiles, and the extreme lines represent the highest and lowest values excluding outliers. The code for raincloud plot visualization has been adapted from Allen et al. [99].

no significant differences between groups in regards to head motion parameters. See supplementary for exclusion criteria and assessed differences between groups.

Independent component analysis. There was a good agreement between most of the components identified in our analysis and the templates provided by Smith et al. [55]. We were able to identify the visual networks $1-3(r=0.80, r=0.73$ and $r=0.64$, respectively), the cerebellar network $(r=0.38)$, the auditory network $(r=0.43)$, the executive control network $(r=0.58)$ and the frontoparietal networks $1(r=0.50)$ and $2(r=0.47)$. In contrast, we were not able to assign a single component to the DMN and the sensorimotor network, as these networks were split up in sub-components, as already observed in multiple studies [58-60]. The DMN consisted of two components (anterior DMN: $r=0.34$ and posterior DMN: $r=0.52$ ) and the sensorimotor network consisted of three components (somatosensory network: $r=0.40$, lateral motor network: $r=0.32$, medial motor network: $r=0.24$ ). In order to allow a comprehensive exploration, we decided to include all of these components in further analysis. For this purpose, the respective sub-components were labeled according to common terminology [60] but in deviation from previous work [55] (i.e., the components were labeled as anterior and posterior DMN, medial and lateral motor network, and somatosensory network). The remaining seven components reflected noise or networks that were not relevant for this analysis.

Within-network connectivity. Within the respective network, significantly less coactivation under the drug condition relative to placebo was found in visual network 1 and 2, both subcomponents

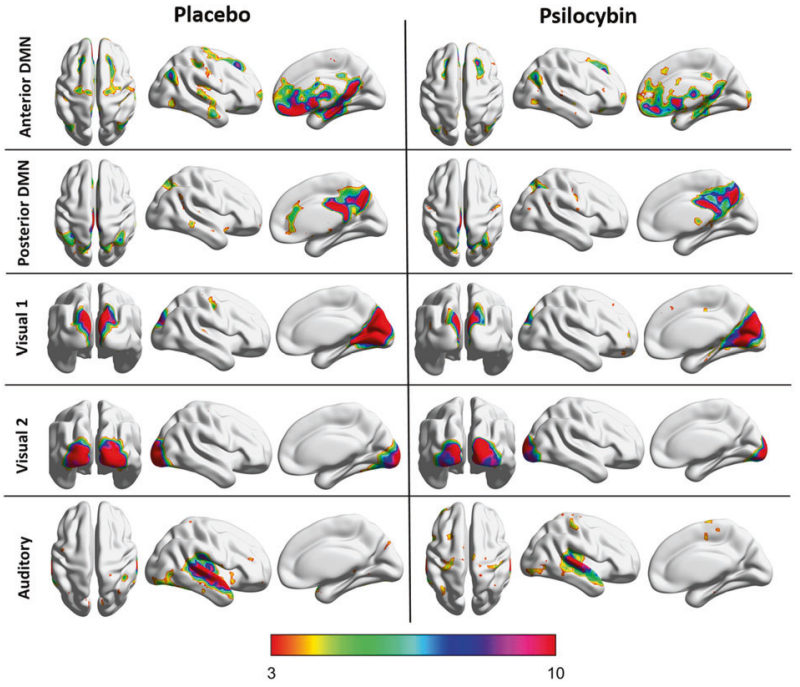

Fig. 3 Within-network resting state functional connectivity. Resting state networks that demonstrated significant differences in within-network functional connectivity, for each group (placebo and psilocybin).

of the DMN (anterior and posterior), and the auditory network (Fig. 3; Table S4).

Between-network connectivity. Widespread increases in betweennetwork FC were observed under psilocybin compared to placebo. 
Me, myself, bye: regional alterations in glutamate and the experience of... NL Mason et al.

\begin{tabular}{|c|c|c|c|c|c|c|c|}
\hline Variable & \multicolumn{3}{|c|}{ Function 1} & \multicolumn{4}{|c|}{ Function 2} \\
\hline Oceanic boundlessness & -1.439 & -0.568 & 32.2 & 0.322 & -0.689 & 47.5 & 79.7 \\
\hline Anxious ego dissolution & -0.810 & -0.681 & 46.4 & 0.727 & -0.365 & 13.3 & $\overline{59.7}$ \\
\hline Glutamate/tCr hippocampus & -0.648 & 0.113 & 1.3 & 1.102 & $\underline{0.990}$ & 98.0 & $\underline{99.3}$ \\
\hline Glutamate/tCr mPFC & -0.724 & -0.630 & 40.0 & 0.036 & $-\overline{0.047}$ & 0.2 & $\overline{40.2}$ \\
\hline Anterior DMN & 0.853 & $\underline{0.520}$ & 27.0 & -0.166 & 0.400 & 16.0 & 43.0 \\
\hline Posterior DMN & 0.551 & $\overline{0.313}$ & 9.7 & -0.047 & $\underline{0.484}$ & 23.4 & 33.1 \\
\hline
\end{tabular}

Coef standardized canonical function coefficients, $r_{s}$ structure coefficients, $r_{s}^{2}$ squared structure coefficient, $h^{2}$ communality coefficient, $R_{c}{ }^{2}$ squared canonical coefficient.

Except the lateral motor network, all investigated networks were affected to some extent (Table S5).

Relationship between psilocybin-induced changes in brain and behavior

A canonical correlation analysis was conducted using the four biological variables as predictors of the three ego dissolution variables, to evaluate the multivariate shared relationship between the two variable sets. The analysis yielded three functions with squared canonical correlations $\left(R_{c}{ }^{2}\right)$ of $0.363,0.282$, and 0.253 for each successive function. The full model across all functions was statistically significant $F(12,61.14)=2.47, p=0.008$ ), explaining $65.9 \%$ of the variance.

Given the $R_{c}{ }^{2}$ effects for each function, the first two functions were significant $(p=0.008$ and $p=0.016$, respectively) and considered noteworthy in the context of this study, with function 1 explaining $36.3 \%$ of the variance, and function 2 explaining $28.2 \%$ of the variance.

Table 2 presents the standardized canonical function coefficients, the structure coefficients $\left(r_{s}\right)$, and the squared structure coefficients $\left(r_{s}^{2}\right)$ for functions 1 and 2, as well as the communalities $\left(h^{2}\right)$ across the two functions for each variable. Function 1 indicated that the dominant contributor was anxious ego dissolution (AED), with oceanic boundlessness (OB) making a secondary contribution. In regards to predictors, MPFC glutamate was the dominant predictor, with anterior DMN FC making a secondary contributions. These results suggest that the strongest predictor of negatively experienced ego dissolution (i.e., AED) was the increase in $\mathrm{mPFC}$ glutamate.

Function 2 indicated that the dominant contributor was ratings on the EDI, with $\mathrm{OB}$ as a secondary contribution. As for the predictors, hippocampal glutamate was the strongest predictor, with posterior DMN FC making a secondary contribution. These results suggest that the strongest predictor of positively experienced ego dissolution was the decrease in hippocampal glutamate.

\section{DISCUSSION}

The present study demonstrates the first attempt to assess the acute effects of psilocybin on glutamate levels in key areas of the human brain, which may play a major role in the actions of serotonergic psychedelics. Using an ultra-high field multimodal MRI approach, we demonstrated that, compared with placebo, psilocybin-induced region-dependent alterations in neurometabolite concentrations. Specifically, participants who received psilocybin demonstrated higher relative glutamate concentration levels in the MPFC, and lower relative glutamate concentration levels in the hippocampus. Analyses indicated that regiondependent alterations in glutamate were also correlated with different dimensions of ego dissolution. Whereas changes in mPFC glutamate were found to be the strongest predictor of negatively experienced ego dissolution, changes in hippocampal glutamate were found to be the strongest predictor of positively experienced ego dissolution.

Previous studies have demonstrated that the MPFC is highly enriched with $5-\mathrm{HT}_{2 \mathrm{~A}}$ receptors located primarily on layer $\mathrm{V}$ pyramidal neurons [61], and modulate excitatory transmission in cortical circuits $[43,62,63]$. Preclinical studies have demonstrated that activation of such receptors via serotonergic psychedelics results in a predominantly excitatory response $[18,64]$ via an increase in glutamate release, as observed in humans for the first time in this study. A glutamatergic increase in this area is also in accordance with human functional imaging studies which have demonstrated a hyperfrontal regional cerebral blood flow (CBF) pattern after psilocybin [46, 65], and similar $5-\mathrm{HT}_{2 \mathrm{~A}}$ agonist psychedelics $[66,67]$. However, we also found that psilocybin administration was associated with higher levels of GABA in this area, results in line with findings that $5-\mathrm{HT}_{2 \mathrm{~A}}$ receptors are also located on GABAergic interneurons $[17,68]$. Taken together, findings suggest that activation of $5-\mathrm{HT}_{2 \mathrm{~A}}$ receptors in the mPFC results in both excitation and inhibition of cortical pyramidal cells [17], potentially resulting in an increased metabolic rate in this area, but not necessarily increased neural input or output.

In contrast to the MPFC, the present study demonstrated that participants who received psilocybin demonstrated lower relative glutamate concentrations in the hippocampus, suggesting that psilocybin decreases glutamate in this area. Such a decrease is in line with data from a recent functional imaging study with psilocybin, demonstrating reduced absolute CBF in the hippocampus compared with placebo [69], of which the authors proposed two potential mechanisms. Namely, decrements could be due to agonism of $5-\mathrm{HT}_{2 \mathrm{~A}}$ receptors located on GABAergic interneurons [44], which can indirectly inhibit pyramidal neurons, decreasing activation in this area. Conversely, it has also been established that, along with the $5-\mathrm{HT}_{2 \mathrm{~A}}$ receptor, psilocin also has a high affinity for the $5-\mathrm{HT}_{1 \mathrm{~A}}$ receptor $[70,71]$. Referred to as serotonin's principal inhibitory receptor [72], the $5-\mathrm{HT}_{1 \mathrm{~A}}$ receptors highest density is found in the limbic regions of the brain such as the hippocampus [73] where it is expressed on neurons that are postsynaptic to the serotonergic input. Thus lower levels in glutamate as seen in this study, as well as regional decreases reflected in others [69], could be due to activation of postsynaptic inhibitory $5-\mathrm{HT}_{1 \mathrm{~A}}$ receptors. Nevertheless, due to methodological 
limitations, this study is not able to delineate which mechanism is contributing to the lower levels in glutamate. Further information could have been potentially gained from quantification of GABA in the hippocampus, however we were unable to reliably do so, due to inherent quantification challenges when assessing GABA levels, arising from low brain concentration levels, metabolite signal overlap, and low signal-to-noise in the hippocampus [74, 75]. Future studies with sequences developed to specifically quantify GABA in low signal-to-noise areas should make further attempts to do so, given recent research implicating hippocampal GABA in the pathology of disorders that psychedelics are being investigated to treat [76].

In the current study, psilocybin induced previously established key features of a psychedelic experience: increases in feelings of ego dissolution, and disrupted RSN activity. Psilocybin increased scores on all dimensions of the 5D-ASC [16], as well as on the EDI [1]. In addition, psilocybin altered within-network FC similarly as has been shown with LSD, including decrements in coactivation within the DMN, visual network 1, and the auditory network $[32,33]$. Finally, we demonstrated higher between-network FC across all networks, which is similar with previous studies assessing the same after psilocybin [35, 42] and LSD [32, 33].

Finally, we assessed the relationship between psilocybininduced changes in the brain, and the subjective experience of sense of self. Canonical correlations were conducted to predict increases in ratings of $A E D$, the dimension encompassing the loss of autonomy and self-control of thought processes, intentionality, decision making, and spontaneous movements [46]. Our data support the conclusion that increasing levels of MPFC glutamate were the strongest predictor in regards to feelings of AED, with decreasing anterior DMN FC and hippocampal glutamate being secondary predictors. These findings are in line with previous work, implicating increased frontal metabolism in feelings of AED after psilocybin [46] and ego pathology in the ketamine model of psychosis [77]. Interestingly, AED-associated changes in mood include paranoia, heightened arousal and attention to the surroundings, and anxiety [46]. A paradoxical effect of serotonergic psychedelics is that acutely they have been found to increase feelings of anxiety $[6,78]$, whereas clinical trials with psychedelic drugs suggest long-term anxiety relief in patients [11, 12, 14]. Accordingly, there is a wide range of animal and human pharmacological evidence supporting the role of the glutamatergic system in anxiety [79], with increases in glutamate in the frontal cortex associated with high versus low state-trait anxiety [80], and reductions corresponding to anxiety-related symptomatic relief [81]. Taken together, the finding that mPFC glutamate was by far the strongest predictor of increased feelings of anxiety, one could propose that acute psychedelic-induced anxiety may be due to localized glutamate-induced hyperfrontality, whereas longterm reductions could be due to agonist-induced $5-\mathrm{HT}_{2 \mathrm{~A}}$ receptor downregulation in this area [72, 82]. Nonetheless, future studies should assess long-term changes in $5-\mathrm{HT}_{2 \mathrm{~A}}$ receptor function in the $\mathrm{mPFC}$, and their relation with subjective effects.

We also assessed the relationship between psilocybin-induced brain changes and feelings of positively experienced ego dissolution, including ratings on the $\mathrm{EDI}$, and scores of $\mathrm{OB}$ on the 5D-ASC. We found that the primary predictor of positively experienced ego dissolution was a decrement in hippocampal glutamate, with secondary contributions of mPFC glutamate and posterior DMN integrity. Previous work has implicated both the MTL (containing the hippocampus) and DMN circuitry in the neural correlates of the self [49]. Namely, abnormal function of MTL regions have been implicated in psychotic states $[83,84]$ and feelings of depersonalization [85] and ego-disturbances [86]. Similarly, studies of drug-induced ego dissolution have found that the decoupling of MTL regions such as the parahippocampus and the DMN correlate positively with feelings of ego dissolution $[49,87]$, with this decoupling being hypothesized to be one of the main underlying mechanisms of the subjective experience [4749]. In regards to why this gives rise to ego dissolution, it has been suggested that psychedelic drug-induced decoupling of these regions results in a temporary loss of access of semantic autobiographical information, resulting in a breakdown of one's personal identity [87]. Our data add to this hypothesis, suggesting that modulations of hippocampal glutamate in particular may be a key mediator in the decoupling underlying feelings of (positive) ego dissolution. Interestingly, although the DMN has been the most implicated RSN in this process, Lebedev et al. [49] found that increases in ego dissolution correlated with decreased FC between the parahippocampal formation and other major networks, such as the salience, frontoparietal, and sensorimotor network; suggesting a key role in this area in particular, as our data also demonstrate. However future research should further assess the contribution of other areas to this experience, such as the posterior cingulate cortex.

Implications of these findings also extend far beyond understanding the neurobiology of the acute psychedelic experience and drug-induced ego dissolution. There is growing evidence that psychedelics can provide therapeutic relief for individuals suffering from increasingly common and difficult to treat disorders such as depression, anxiety, addiction, and post-traumatic stress disorders $[4,9,11,88,89]$. Thus understanding the mechanisms by which psychedelics provide symptomatic relief may identify novel therapeutic targets. Interestingly, the degree of ego dissolution has been found to correlate with long-term clinical outcomes [90] and increases in well-being [10,91]. In addition, a hypothetical (neurobiological) model has been proposed to explain the long-term effects witnessed in clinical trials. It has been suggested that indirect activation of glutamate networks via $5-\mathrm{HT}_{2 \mathrm{~A}}$ receptor agonism increases $\mathrm{BDNF}$, and ultimately enhances neuroplasticity [16]. In line with this, it has been shown in preclinical models that psychedelics increase functional and structural neuroplasticity [92], however evidence in humans is limited, due to restrictions of methodological techniques. Our data provide indirect evidence that psychedelics might have the potential to increase neuroplasticity in the human cortex via increased glutamatergic activity, but not in the hippocampus; findings that are in accordance with previous $5-\mathrm{HT}_{2 \mathrm{~A}}$ receptor activation studies [27, 93, 94]. In addition, psilocybin administration was associated with higher levels of MPFC NAA, a compound regarded as a measure of neuronal viability and function, and decreased in disorders associated with regional neuronal loss and disrupted neuronal function [95].

Of note, compared to previous psychedelic studies, the dose administered was low to moderate [96], and thus not high enough to induce total ego dissolution. However, the aim of this study was not to assess maximal effects of psilocybin, but rather an effective dose that would induce a relevant psychedelic state that participants could endure in the MRI scanner. Our data demonstrate that the dose was effective, inducing significantly higher levels of both positively and negatively experienced ego dissolution compared with placebo, as well as the other subjective effects representative of a psychedelic state (Figs. 1, S1). Furthermore, although BOLD sensitivity is increased by the use of ultra-high magnetic fields, geometric distortions become more prominent, which could have affected our BOLD signal in inferior brain regions [97], and our scan time was arguably short from a test-retest reliability standpoint [98]. Nevertheless, our results are similar to aforementioned studies [32, 33, 35, 42] who acquired their data at a lower field strength, with varying scanning lengths. Finally, an inherent difficulty of studying substances with such salient subjective effects is maintaining the treatment blind. Thus, it could be suggested that participant recognition of the treatment condition could affect neural and subjective results, emphasizing the importance of active placebo conditions or crosspsychotropic comparisons in future trials. 
Me, myself, bye: regional alterations in glutamate and the experience of... NL Mason et al.

In conclusion, our data demonstrate that the serotonergic psychedelic, psilocybin, acutely induces region dependent alterations in glutamate that correlate with established behavioral changes during the psychedelic state. Such findings provide further insights into the underlying neurobiological mechanisms of the psychedelic state, and importantly, provide a neurochemical basis for how these substances alter individuals' sense of self, and may be giving rise to therapeutic effects witnessed in ongoing clinical trials.

\section{FUNDING AND DISCLOSURE}

This study is part of the Beckley/Maastricht Research Programme. The Beckley Foundation made a financial contribution to the study. The authors report no other relevant funding, and all authors report no potential conflicts of interest.

\section{ACKNOWLEDGEMENTS}

The authors would like to thank Cees van Leeuwen for medical supervision, Fulya Onus and Sofia Rocha for their assistance with data collection, Professor Robert Leech for analysis advice, all reviewers for their help in improving the manuscript, and all participants for their time and effort.

\section{AUTHOR CONTRIBUTIONS}

$\mathrm{NM}, \mathrm{KK}, \mathrm{JG}$, and AF designed the research. NM, JR, and NH performed the research. DT set up and made all of the MRI/MRS possible. JJ provided analysis tools. NM and FM analyzed the data. All authors made a substantial contribution to interpretation of the data and drafting of the manuscript.

\section{REFERENCES}

1. Nour MM, Evans L, Nutt D, Carhart-Harris RL. Ego-dissolution and psychedelics: validation of the ego-dissolution inventory (EDI). Front Hum Neurosci. 2016;10:269.

2. Studerus E, Gamma A, Vollenweider FX. Psychometric evaluation of the altered states of consciousness rating scale (OAV). PLoS ONE. 2010;5:e12412.

3. Nour MM, Carhart-Harris RL. Psychedelics and the science of self-experience. Br J Psychiatry: J Ment Sci. 2017;210:177-9.

4. Carhart-Harris RL, Bolstridge M, Rucker J, Day CMJ, Erritzoe D, Kaelen M, et al. Psilocybin with psychological support for treatment-resistant depression: an open-label feasibility study. Lancet Psychiatry. 2016;3:619-27.

5. Carhart-Harris RL, Goodwin GM. The therapeutic potential of psychedelic drugs: past, present, and future. Neuropsychopharmacology. 2017;42:2105-13.

6. Griffiths RR, Richards WA, McCann U, Jesse R. Psilocybin can occasion mysticaltype experiences having substantial and sustained personal meaning and spiritual significance. Psychopharmacology. 2006;187:268-83. discussion 84-92

7. Griffiths RR, Richards WA, Johnson MW, McCann UD, Jesse R. Mystical-type experiences occasioned by psilocybin mediate the attribution of personal meaning and spiritual significance 14 months later. J Psychopharmacol. 2008;22:621-32.

8. Mason NL, Mischler E, Uthaug MV, Kuypers KP. Sub-acute effects of psilocybin on empathy, creative thinking, and subjective well-being. J Psychoact Drugs. 2019:51:123-34

9. Johnson MW, Garcia-Romeu A, Griffiths RR. Long-term follow-up of psilocybinfacilitated smoking cessation. Am J drug alcohol Abus. 2017;43:55-60.

10. Uthaug MV, van Oorsouw K, Kuypers KPC, van Boxtel M, Broers NJ, Mason NL, et al. Sub-acute and long-term effects of ayahuasca on affect and cognitive thinking style and their association with ego dissolution. Psychopharmacology. 2018;235:1-11.

11. Griffiths RR, Johnson MW, Carducci MA, Umbricht A, Richards WA, Richards BD, et al. Psilocybin produces substantial and sustained decreases in depression and anxiety in patients with life-threatening cancer: a randomized double-blind trial. J Psychopharmacol. 2016;30:1181-97.

12. Gasser P, Holstein D, Michel Y, Doblin R, Yazar-Klosinski B, Passie T, et al. Safety and efficacy of lysergic acid diethylamide-assisted psychotherapy for anxiety associated with life-threatening diseases. J Nerv Ment Dis. 2014;202:513-20.

13. Palhano-Fontes F, Barreto D, Onias H, Andrade KC, Novaes MM, Pessoa JA, et al. Rapid antidepressant effects of the psychedelic ayahuasca in treatmentresistant depression: a randomized placebo-controlled trial. Psychol Med. 2019;49:655-63.
14. Grob CS, Danforth AL, Chopra GS, Hagerty M, McKay CR, Halberstadt AL, et al. Pilot study of psilocybin treatment for anxiety in patients with advanced-stage cancer. Arch Gen Psychiatry. 2011;68:71-8.

15. Sanches RF, de Lima Osorio F, Dos Santos RG, Macedo LR, Maia-de-Oliveira JP, Wichert-Ana $L$, et al. Antidepressant effects of a single dose of Ayahuasca in patients with recurrent depression: a SPECT study. J Clin Psychopharmacol. 2016;36:77-81.

16. Vollenweider FX, Kometer M. The neurobiology of psychedelic drugs: implications for the treatment of mood disorders. Nat Rev Neurosci. 2010;11:642-51.

17. Nichols DE. Psychedelics. Pharmacol Rev. 2016;68:264-355.

18. Aghajanian GK, Marek GJ. Serotonin induces excitatory postsynaptic potentials in apical dendrites of neocortical pyramidal cells. Neuropharmacology. 1997:36:589-99.

19. Aghajanian GK, Marek GJ. Serotonin, via 5-HT2A receptors, increases EPSCs in layer $\mathrm{V}$ pyramidal cells of prefrontal cortex by an asynchronous mode of glutamate release. Brain Res. 1999;825:161-71.

20. Glennon RA, Titeler M, McKenney J. Evidence for 5-HT2 involvement in the mechanism of action of hallucinogenic agents. Life Sci. 1984;35:2505-11.

21. Wing LL, Tapson GS, Geyer MA. 5HT-2 mediation of acute behavioral effects of hallucinogens in rats. Psychopharmacology. 1990;100:417-25.

22. Sipes T, Geyer M. DOI disruption of prepulse inhibition of startle in the rat is mediated by $5-\mathrm{HT} 2 \mathrm{~A}$ and not by $5-\mathrm{HT} 2 \mathrm{C}$ receptors. Behav Pharmacol. 1995;6:83942.

23. Scruggs IL, Schmidt D, Deutch AY. The hallucinogen 1-[2,5-dimethoxy-4-iodophenyl]-2-aminopropane (DOI) increases cortical extracellular glutamate levels in rats. Neurosci Lett. 2003;346:137-40.

24. Scruggs JL, Patel S, Bubser M, Deutch AY. DOI-induced activation of the cortex dependence on 5 -HT2A heteroceptors on thalamocortical glutamatergic neurons. J Neurosci. 2000;20:8846-52.

25. Puig MV, Celada P, Díaz-Mataix $L$, Artigas F. In vivo modulation of the activity of pyramidal neurons in the rat medial prefrontal cortex by $5-\mathrm{HT} 2 \mathrm{~A}$ receptors: relationship to thalamocortical afferents. Cereb Cortex. 2003;13:870-82.

26. Béique J-C, Imad M, Mladenovic L, Gingrich JA, Andrade R. Mechanism of the 5hydroxytryptamine $2 \mathrm{~A}$ receptor-mediated facilitation of synaptic activity in prefrontal cortex. Proc Natl Acad Sci USA. 2007;104:9870-5.

27. Vaidya VA, Marek GJ, Aghajanian GK, Duman RS. 5-HT2A receptor-mediated regulation of brain-derived neurotrophic factor $\mathrm{mRNA}$ in the hippocampus and the neocortex. J Neurosci. 1997;17:2785-95.

28. Cavus I, Duman RS. Influence of estradiol, stress, and 5-HT2A agonist treatment on brain-derived neurotrophic factor expression in female rats. Biol Psychiatry. 2003;54:59-69.

29. Martinowich $\mathrm{K}$, Manji $\mathrm{H}$, Lu B. New insights into BDNF function in depression and anxiety. Nat Neurosci. 2007;10:1089.

30. Carhart-Harris RL, Erritzoe D, Williams T, Stone JM, Reed LJ, Colasanti A, et al Neural correlates of the psychedelic state as determined by fMRI studies with psilocybin. Proc Natl Acad Sci USA. 2012;109:2138-43.

31. Smigielski L, Scheidegger M, Kometer M, Vollenweider FX. Psilocybin-assisted mindfulness training modulates self-consciousness and brain default mode network connectivity with lasting effects. Neurolmage. 2019;196:207-15.

32. Müller F, Dolder PC, Schmidt A, Liechti ME, Borgwardt S. Altered network hub connectivity after acute LSD administration. Neurolmage: Clin. 2018;18:694-701.

33. Carhart-Harris RL, Muthukumaraswamy S, Roseman L, Kaelen M, Droog W, Murphy $K$, et al. Neural correlates of the LSD experience revealed by multimodal neuroimaging. Proc Natl Acad Sci USA. 2016;113:4853-8.

34. Palhano-Fontes F, Andrade KC, Tofoli LF, Santos AC, Crippa JAS, Hallak JE, et al. The psychedelic state induced by ayahuasca modulates the activity and connectivity of the default mode network. PLoS ONE. 2015;10:e0118143.

35. Roseman L, Leech R, Feilding A, Nutt DJ, Carhart-Harris RL. The effects of psilocybin and MDMA on between-network resting state functional connectivity in healthy volunteers. Front Hum Neurosci. 2014;8. https://doi.org/10.3389/ fnhum.2014.00204.

36. Lord L-D, Expert P, Atasoy S, Roseman L, Rapuano K, Lambiotte R, et al. Dynamical exploration of the repertoire of brain networks at rest is modulated by psilocybin. Neurolmage. 2019;199:127-42.

37. Andrews-Hanna JR. The brain's default network and its adaptive role in internal mentation. Neuroscientist. 2012;18:251-70.

38. Raichle ME, MacLeod AM, Snyder AZ, Powers WJ, Gusnard DA, Shulman GL. A default mode of brain function. Proc Natl Acad Sci USA. 2001;98:676-82.

39. Davey CG, Pujol J, Harrison BJ. Mapping the self in the brain's default mode network. Neurolmage. 2016;132:390-7.

40. Atasoy S, Roseman L, Kaelen M, Kringelbach ML, Deco G, Carhart-Harris RL. Connectome-harmonic decomposition of human brain activity reveals dynamical repertoire re-organization under LSD. Sci Rep. 2017;7:17661. 
41. Tagliazucchi E, Roseman L, Kaelen M, Orban C, Muthukumaraswamy SD, Murphy $\mathrm{K}$, et al. Increased global functional connectivity correlates with LSD-induced ego dissolution. Curr Biol. 2016;26:1043-50.

42. Carhart-Harris RL, Leech R, Erritzoe D, Williams TM, Stone JM, Evans J, et al. Functional connectivity measures after psilocybin inform a novel hypothesis of early psychosis. Schizophrenia Bull. 2013;39:1343-51.

43. Andrade R. Serotonergic regulation of neuronal excitability in the prefrontal cortex. Neuropharmacology. 2011;61:382-6.

44. Bombardi C, Di Giovanni G. Functional anatomy of 5-HT2A receptors in the amygdala and hippocampal complex: relevance to memory functions. Exp Brain Res. 2013;230:427-39.

45. Puig MV, Gulledge AT. Serotonin and prefrontal cortex function: neurons, networks, and circuits. Mol Neurobiol. 2011;44:449-64.

46. Vollenweider F, Leenders K, Scharfetter C, Maguire P, Stadelmann O, Angst J. Positron emission tomography and fluorodeoxyglucose studies of metabolic hyperfrontality and psychopathology in the psilocybin model of psychosis. Neuropsychopharmacology. 1997;16:357-72.

47. Carhart-Harris RL, Leech R, Hellyer PJ, Shanahan M, Feilding A, Tagliazucchi E, et al. The entropic brain: a theory of conscious states informed by neuroimaging research with psychedelic drugs. Front Hum Neurosci. 2014;8.

48. Carhart-Harris RL, Friston KJ. The default-mode, ego-functions and free-energy: a neurobiological account of Freudian ideas. Brain: J Neurol. 2010;133(Pt 4):1265-83.

49. Lebedev AV, Lövdén M, Rosenthal G, Feilding A, Nutt DJ, Carhart-Harris RL. Finding the self by losing the self: Neural correlates of ego-dissolution under psilocybin. Hum Brain Mapp. 2015;36:3137-53.

50. Dittrich A. The standardized psychometric assessment of altered states of consciousness (ASCs) in humans. Pharmacopsychiatry. 1998;31(S 2):80-4.

51. Frahm J, Bruhn H, Gyngell ML, Merboldt KD, Hanicke W, Sauter R. Localized highresolution proton NMR spectroscopy using stimulated echoes: initial applications to human brain in vivo. Magn Reson Med. 1989;9:79-93.

52. Near J, Harris AD, Juchem C, Kreis R, Marjanska M, Oz G, et al. Preprocessing, analysis and quantification in single-voxel magnetic resonance spectroscopy: experts' consensus recommendations. NMR Biomed. 2020:e4257. https://doi.org/ $10.1002 / \mathrm{nbm} .4257$

53. Whitfield-Gabrieli S, Nieto-Castanon A. Conn: a functional connectivity toolbox for correlated and anticorrelated brain networks. Brain Connect. 2012;2:125-41.

54. Calhoun VD, Adali T, Pearlson GD, Pekar JJ. A method for making group inferences from functional MRI data using independent component analysis. Hum Brain Mapp. 2001;14:140-51.

55. Smith SM, Fox PT, Miller KL, Glahn DC, Fox PM, Mackay CE, et al. Correspondence of the brain's functional architecture during activation and rest. Proc Natl Acad Sci USA. 2009;106:13040-5.

56. Sherry A, Henson RK. Conducting and interpreting canonical correlation analysis in personality research: a user-friendly primer. J Personal Assess. 2005;84:37-48.

57. Brown RT, Nicholas CR, Cozzi NV, Gassman MC, Cooper KM, Muller D, et al. Pharmacokinetics of escalating doses of oral psilocybin in healthy adults. Clin Pharmacokinet. 2017. https://doi.org/10.1007/s40262-017-0540-6.

58. Abou-Elseoud A, Starck T, Remes J, Nikkinen J, Tervonen O, Kiviniemi V. The effect of model order selection in group PICA. Hum Brain Mapp. 2010;31:1207-16.

59. Allen EA, Erhardt EB, Damaraju E, Gruner W, Segall JM, Silva RF, et al. A baseline for the multivariate comparison of resting-state networks. Front Syst Neurosci. 2011;5:2.

60. Oldehinkel M, Mennes M, Marquand A, Charman T, Tillmann J, Ecker C, et al. Altered connectivity between cerebellum, visual, and sensory-motor networks in autism spectrum disorder: results from the EU-AIMS Longitudinal European Autism Project. Biol Psychiatry: Cogn Neurosci Neuroimaging. 2019;4:260-70.

61. Weber ET, Andrade R. Htr2a Gene and 5-HT(2A) Receptor expression in the cerebral cortex studied using genetically modified mice. Front Neurosci. 2010;4. https://doi.org/10.3389/fnins.2010.00036.

62. Marek GJ, Aghajanian GK. The electrophysiology of prefrontal serotonin systems: therapeutic implications for mood and psychosis. Biol Psychiatry. 1998;44:1118-27.

63. Lambe EK, Goldman-Rakic PS, Aghajanian GK. Serotonin induces EPSCs preferentially in layer $\mathrm{V}$ pyramidal neurons of the frontal cortex in the rat. Cereb Cortex. 2000;10:974-80.

64. Marek GJ, Aghajanian GK. 5-Hydroxytryptamine-induced excitatory postsynaptic currents in neocortical layer $\mathrm{V}$ pyramidal cells: suppression by mu-opiate receptor activation. Neuroscience. 1998;86:485-97.

65. Gouzoulis-Mayfrank E, Schreckenberger M, Sabri O, Arning C, Thelen B, Spitzer M, et al. Neurometabolic effects of psilocybin, 3, 4-methylenedioxyethylamphetamine (MDE) and d-methamphetamine in healthy volunteers: a double-blind, placebocontrolled PET study with [18F] FDG. Neuropsychopharmacology. 1999;20:565-81.

66. Hermle L, Fünfgeld M, Oepen G, Botsch H, Borchardt D, Gouzoulis E, et al. Mescaline-induced psychopathological, neuropsychological, and neurometabolic effects in normal subjects: experimental psychosis as a tool for psychiatric research. Biol Psychiatry. 1992;32:976-91.
67. Riba J, Romero S, Grasa E, Mena E, Carrio I, Barbanoj MJ. Increased frontal and paralimbic activation following ayahuasca, the pan-Amazonian inebriant. Psychopharmacology. 2006;186:93-8.

68. Zhou F-M, Hablitz JJ. Activation of serotonin receptors modulates synaptic transmission in rat cerebral cortex. J Neurophysiol. 1999;82:2989-99.

69. Lewis $C R$, Preller $\mathrm{KH}$, Kraehenmann $\mathrm{R}$, Michels $\mathrm{L}$, Staempfli $\mathrm{P}$, Vollenweider FX. Two dose investigation of the 5-HT-agonist psilocybin on relative and global cerebral blood flow. Neuroimage. 2017;159:70-8.

70. McKenna DJ, Repke DB, Lo L, Peroutka SJ. Differential interactions of indolealkylamines with 5-hydroxytryptamine receptor subtypes. Neuropharmacology. 1990;29:193-8.

71. Blair JB, Kurrasch-Orbaugh D, Marona-Lewicka D, Cumbay MG, Watts VJ, Barker $\mathrm{EL}$, et al. Effect of ring fluorination on the pharmacology of hallucinogenic tryptamines. J Med Chem. 2000;43:4701-10.

72. Carhart-Harris R, Nutt D. Serotonin and brain function: a tale of two receptors. J Psychopharmacol. 2017;31:1091-120.

73. Hamon M, Gozlan H, el Mestikawy S, Emerit MB, Bolanos F, Schechter L. The central 5-HT1A receptors: pharmacological, biochemical, functional, and regulatory properties. Ann NY Acad Sci. 1990;600:114-29. discussion 29-31

74. Puts NAJ, Edden RAE. In vivo magnetic resonance spectroscopy of GABA: a methodological review. Prog Nucl Magn Reson Spectrosc. 2012;60:29-41.

75. Shungu DC, Mao X, Gonzales R, Soones TN, Dyke JP, van der Veen JW, et al. Brain gamma-aminobutyric acid (GABA) detection in vivo with the J-editing (1) H MRS technique: a comprehensive methodological evaluation of sensitivity enhancement, macromolecule contamination and test-retest reliability. NMR Biomed. 2016;29:932-42.

76. Schmitz TW, Correia MM, Ferreira CS, Prescot AP, Anderson MC. Hippocampal GABA enables inhibitory control over unwanted thoughts. Nat Commun. 2017;8:1311.

77. Vollenweider F, Leenders K, Scharfetter C, Antonini A, Maguire P, Missimer J, et al. Metabolic hyperfrontality and psychopathology in the ketamine model of psychosis using positron emission tomography (PET) and [18F] fluorodeoxyglucose (FDG). Eur Neuropsychopharmacol. 1997;7:9-24.

78. Carhart-Harris RL, Kaelen M, Bolstridge M, Williams T, Williams L, Underwood R, et al. The paradoxical psychological effects of lysergic acid diethylamide (LSD). Psycholog Med. 2016;46:1379-90.

79. Cortese BM, Phan KL. The role of glutamate in anxiety and related disorders. CNS Spectr. 2005;10:820-30.

80. Grachev ID, Apkarian AV. Chemical mapping of anxiety in the brain of healthy humans: an in vivo $1 \mathrm{H}-\mathrm{MRS}$ study on the effects of sex, age, and brain region. Hum Brain Mapp. 2000;11:261-72.

81. Mathew SJ, Amiel JM, Coplan JD, Fitterling HA, Sackeim HA, Gorman JM. Openlabel trial of riluzole in generalized anxiety disorder. Am J Psychiatry. 2005;162:2379-81.

82. Buckholtz NS, Zhou DF, Freedman DX, Potter WZ. Lysergic acid diethylamide (LSD) administration selectively downregulates serotonin2 receptors in rat brain. Neuropsychopharmacology. 1990;3:137-48.

83. Acioly MA, Carvalho $\mathrm{CH}$, Tatagiba $\mathrm{M}$, Gharabaghi $\mathrm{A}$. The parahippocampal gyrus as a multimodal association area in psychosis. J Clin Neurosci. 2010;17:1603-5.

84. Friston $\mathrm{K}$, Liddle $\mathrm{P}$, Frith $\mathrm{C}$, Hirsch S, Frackowiak R. The left medial temporal region and schizophrenia: a PET study. Brain. 1992;115:367-82.

85. Lambert MV, Sierra M, Phillips ML, David AS. The spectrum of organic depersonalization: a review plus four new cases. J Neuropsychiatry Clin Neurosci. 2002;14:141-54.

86. Lemche $E$, Surguladze SA, Brammer MJ, Phillips ML, Sierra M, David AS, et al. Dissociable brain correlates for depression, anxiety, dissociation, and somatization in depersonalization-derealization disorder. CNS Spectr. 2016;21:35-42.

87. Millière R, Carhart-Harris RL, Roseman L, Trautwein F-M, Berkovich-Ohana A. Psychedelics, meditation, and self-consciousness. Front Psychol. 2018;9:1475.

88. Oehen P, Traber R, Widmer V, Schnyder U. A randomized, controlled pilot study of MDMA (+/- 3,4-Methylenedioxymethamphetamine)-assisted psychotherapy for treatment of resistant, chronic Post-Traumatic Stress Disorder (PTSD). J Psychopharmacol. 2013;27:40-52.

89. Garcia-Romeu A, Griffiths RR, Johnson MW. Psilocybin-occasioned mystical experiences in the treatment of tobacco addiction. Curr Drug Abus Rev. 2015;7:157-64

90. Roseman L, Nutt DJ, Carhart-Harris RL. Quality of acute psychedelic experience predicts therapeutic efficacy of psilocybin for treatment-resistant depression. Front Pharmacol. 2017;8:974.

91. Uthaug M, Lancelotta R, van Oorsouw K, Kuypers K, Mason N, Rak J, et al. A single inhalation of vapor from dried toad secretion containing 5-methoxy- $\mathrm{N}, \mathrm{N}$ dimethyltryptamine (5-MeO-DMT) in a naturalistic setting is related to sustained enhancement of satisfaction with life, mindfulness-related capacities, and a decrement of psychopathological symptoms. Psychopharmacology. 2019;236:1-14. 
Me, myself, bye: regional alterations in glutamate and the experience of... NL Mason et al.

92. Ly C, Greb AC, Cameron LP, Wong JM, Barragan EV, Wilson PC, et al. Psychedelics promote structural and functional neural plasticity. Cell Rep. 2018;23:3170-82.

93. Gewirtz JC, Chen AC, Terwilliger R, Duman RC, Marek GJ. Modulation of DOIinduced increases in cortical BDNF expression by group II mGlu receptors. Pharmacol, Biochem, Behav. 2002;73:317-26.

94. Jones KA, Srivastava DP, Allen JA, Strachan RT, Roth BL, Penzes P. Rapid modulation of spine morphology by the 5-HT2A serotonin receptor through kalirin-7 signaling. Proc Natl Acad Sci USA. 2009;106:19575-80.

95. Manji HK, Moore GJ, Rajkowska G, Chen G. Neuroplasticity and cellular resilience in mood disorders. Mol Psychiatry. 2000;5:578-93.

96. Studerus E, Kometer M, Hasler F, Vollenweider FX. Acute, subacute and long-term subjective effects of psilocybin in healthy humans: a pooled analysis of experimental studies. J Psychopharmacol. 2011;25:1434-52.

97. Jezzard P. Correction of geometric distortion in fMRI data. Neurolmage. 2012;62:648-51.

98. Birn RM, Molloy EK, Patriat R, Parker T, Meier TB, Kirk GR, et al. The effect of scan length on the reliability of resting-state $\mathrm{fMRI}$ connectivity estimates. Neurolmage. 2013;83:550-8.
99. Allen M, Poggiali D, Whitaker K, Marshall TR, Kievit RA. Raincloud plots: a multiplatform tool for robust data visualization. Wellcome Open Res. 2019;4:63.

(i) Open Access This article is licensed under a Creative Commons Attribution 4.0 International License, which permits use, sharing adaptation, distribution and reproduction in any medium or format, as long as you give appropriate credit to the original author(s) and the source, provide a link to the Creative Commons license, and indicate if changes were made. The images or other third party material in this article are included in the article's Creative Commons license, unless indicated otherwise in a credit line to the material. If material is not included in the article's Creative Commons license and your intended use is not permitted by statutory regulation or exceeds the permitted use, you will need to obtain permission directly from the copyright holder. To view a copy of this license, visit http://creativecommons. org/licenses/by/4.0/.

(c) The Author(s) 2020 